\title{
The multilayered soil-structure seismic interaction and structure vibration mechanism
}

\author{
Abdoullah Namdar \\ Faculty of Architecture and Civil Engineering, Huaiyin Institute of Technology, Huai'an, China \\ Department for Management of Science and Technology Development, Ton Duc Thang University, Ho Chi Minh City, Vietnam \\ Faculty of Environment and Labour Safety, Ton Duc Thang University, Ho Chi Minh City, Vietnam \\ abdoullah.namdar@tdtu.edu.vn
}

\begin{abstract}
The morphology of subsoil influences the soil-structure interaction and it makes complex to predict seismic structural stability. The structural elements seismic response associate to soil-structure interaction requires expansive investigation considering soil morphology. The main objective of the present study is to identify the influence of near-fault ground motion mechanism reached by the structure element for evaluating strain energy modification due to the morphology of subsoil and developing load and displacement on the structural element with built-up synthetic subsoil for soil-structure seismic interaction design. The results of the numerical simulation revealed that (i) the displacement mechanism and the applied seismic load of the structural element, (ii) the strain energy modification and (iii) the structural vibration patterns of continuous beam in a timber frame have been changed in association to the soil foundation characteristics. The innovation of this study is the soil-structure interaction, the soil layers interaction, the near-fault ground motion and the mechanical properties of the soil at different location of the soil foundation, that are fundamental parameters to control continuous timber beam seismic design.
\end{abstract}

KEYwords. Multilayered Soil; Structure; Strain Energy; Displacement; Vibration Patterns.

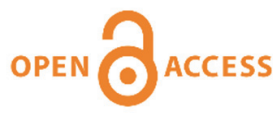

Citation: Namdar, A., The multilayered soilstructure seismic interaction and structure vibration mechanism, Frattura ed Integrità Strutturale, 51 (2020) 267-274.

Received: 14.09 .2019

Accepted: 28.11.2019

Published: 01.01.2020

Copyright: (C) 2020 This is an open access article under the terms of the CC-BY 4.0, which permits unrestricted use, distribution, and reproduction in any medium, provided the original author and source are credited.

\section{INTRODUCTION}

7 he structure seismic response is extremely related to near-fault ground motion characteristics and, on the other hand, due to subsoil morphology at different locations of the earth, the seismic travel paths characteristics are changed during seismic wave travel from the source to the base of the structure. Also, seismic wave changes in the construction site from a location to nearby location considerably, this alters the seismic wave and creates complex prediction for seismic stability of a structure. In the most urban construction site, the buildings behave with different seismic response 
and result in various seismic resistance of different structures while the applied near-fault ground motion was the same from the source and the urban construction site mostly content different soil layers. In the seismic design of the structure, the underground simulation modeling is extremely important to predict seismic response of the structure and subsoil. For structure, seismic design in the urban construction site, not only soil or structure improvement, is applied in the most consultation and research works, and effect of soil in structural element seismic response has not been studied and reported in the literature. In several small projects at the urban construction site is not economic to consider soil, structure, and nearfault ground motion characteristics; however, due to this limitation always many individual small buildings do not have sufficient seismic stability.

The mechanical properties of soils have been investigated in order to analyze liquefaction which is one of a disaster occurring after a strong earthquake, and it has been realized that the site geological structure governs seismic wave which produces the liquefaction in the soil [1]. The tsunami producing dynamic wave in subsoil has been simulated and in order to maintain subsoil dynamic stability the sea forests were proposed to enhance subsoil trough the modification of wave geometry by reducing seawater depth, strengthening soil mechanical properties and preventing tsunami debris transfer debride tsunami to the city after the shear strength of the subsoil reached near zero and liquefaction occurred with maximum magnitude [2], The liquefaction in the coastal line causes the lateral and vertical pressures to the building and subsoil, on the other hand, tsunami may produce debride and, in this case debride accelerates tsunami destructive power, in order to prevent accelerate debride development, dynamic stability of the subsoil is significantly required using advances geotechnical engineering techniques.

The numerical analysis has been used to assess the bearing capacity of different soils under normal and frozen conditions [3-5]. The mechanical properties, the strength and the bearing capacity of soils are very important in soil tension and compressive response during the soil is subjected to the loading in a different direction and it leads to developing displacement and deformation of the soil [6-7]. In other words, strain energy and damage have been investigated to solve several engineering problems and strain energy needs to be investigated further [8-16]. There are several types of research on flexural load applied on structure and materials [17-21]. However, the seismic travel paths characteristics in the urban construction site for identifying seismic wave applied to each individual building has not been investigated and it required expansive investigation. Based on soil seismic response and structures seismic response mechanism, it is required to investigate the bridge between soil response and structure response. The seismic responses of multilayered soil effect on the structural elements seismic response have not been investigated considering strain, displacement and seismic load response for evaluating structural vibration patterns when the near-fault ground motions applied on the model and seismic wave are changed with travel from multilayered soils. In the present study, the numerical analysis has been done to evaluate strain energy modification due to the morphology of subsoil and developing load and displacement of a continuous beam in the timber frame with built-up synthetic subsoil for understanding soil-structure seismic interaction design. However, it is aimed to analyze the energies interaction and the nonlinear displacement of the structural elements. It hopes the outcomes of this research work support in enhancement of the seismic stability of small individual buildings.

\section{MODELING METHODOLOGY, MATERIALS AND SEISMIC LOADING}

7 he soil-structure interaction is a complex problem in geotechnical earthquake engineering and it requires to investigating seismic stability enhancement of structure and soil developing appropriate modeling, to recognize suitable near-fault ground motion and to apply powerful software in order to minimize research cost, to predict in detail the soil-structure interaction model behavior and to produce best seismic design guideline. For understanding the relationship between soil, structural elements and seismic loading excitation, the structure-multilayered soil seismic response is simulated and the near-fault ground motion is applied to the configuration using acceleration history of near-fault ground motion reported in the literature by means of ABAQUS software for performing the numerical simulation. The numerical simulation was performed considering the applied near-fault ground motion and the response of near-fault ground motion in form of strain energy, displacement and seismic load response within the selected structural elements; comparative analysis has been done with two simulated archetypes. The near-fault ground motion response characteristics studied in association with the multilayered soil were configured at two different subsoil models and the structural frame is constant at all configuration. When the two multilayered soils were designed, the structure was modeled with fixed base boundary condition. The multilayered soils interact was simulated using the deformable mesh. Using deformable mesh in the numerical simulation, as the model is subjected to seismic excitation is a supportive technique to develop cyclic graphs for displacement, strain and seismic load response. In studying the simulated configuration, the seismic load response, strain, and displacement are required to realize seismic stiffness and strength of the structural elements and soil at all stages of 
applied seismic loading on the model. However, in comparative soil and structure for the seismic response, the small displacement theory is applicable and the small displacement theory is one of advanced concepts to explain strain energy function in dynamic excitation of soil-structure interaction. In the present study, the nonlinear graphs of the straindisplacement were developed based on the small displacement theory and based on the numerical analysis results the comparation has been made only for structural elements seismic response. The near-fault ground motion mechanism was simulated with seismic load excitation transfer from an element and node to neighboring element and node respectively, the nodes and elements interaction patterns were adopted in the numerical simulation to execute software. After executing the software, the most critical structural elements affected by near-fault ground motion were selected for more detail analysis by depicting the cyclic graphs. The seismic excitation, rest and seismic dissipation of the structural elements have been explained using cyclic graphs.

The acceleration history of near-fault ground motion applied in the numerical simulation is shown in figure 1. The acceleration history was applied to soil basis after seismic wave travelled from the soil layers and seismic wave influenced by soil layer interaction, the seismic wave reached the fixed base of the structure and the seismic excitation transferred within all over the structural elements. Based on the near-fault ground motion excitation and finite element method (FEM), this study discovers the effect of the multilayered soil arrangement on the structural elements seismic stability, understanding seismic soil-structure interaction in reference to the small displacement theory. This numerical simulation is essential in the seismic design of the low-cost individual building. The mechanical properties of the soils and timber have been indicated in table 1 . The previous researches mostly concentrated on the concrete structure-soil interaction and steel structure-soil interaction, while in the present study the timber structure-soil interaction has been investigated and footing, foundation, columns, and beams have been simulated using the timber materials. The timber frame structure as an independent structural system interacts with multilayered soil, and the seismic stability of the timber frame is examined. In order to enhance quality of the soil-timber structure interaction, in the numerical simulation small size of $50 \mathrm{~mm}$ the mesh for timber structure has been selected, and the horizontal and vertical soil-timber footing interaction has been characterized based on the node to node and element to element interaction between the soil and the timber footing. From the point of view of design half of the footing, height was embedded in the soil. In performing the numerical simulation by means of ABAQUS software the combination of the forcing frequency and near-fault ground motion has been adopted and applied to all archetypes simultaneously.

The soils and beams were characterized and depicted in figure 2. The beam was characterized by 12.9 meters length and 0.3 x 0.3 meters cross-section. The column size was the 2.7 -meters length, and $0.3 \times 0.3$ meters of the cross-section in both models. The timber frame was installed on a foundation of $0.3 \times 0.3 \times 0.3$ meters and, beneath the foundation, a footing was designed with dimensions of $0.9 \times 0.9 \times 0.4$ meters. The footing was designed with 0.4 meters height and 0.2 meters of footing height was embedded in the soil foundation. The difference between models 1 and 2 was the soil foundation. Model 1 was built up with the soil-A, and model 2 was built up with the soil-A and soil-B. Model 1 had dimension of 15.3x2.7x1.0 meters and was fully made of soil-A. Model 2 was built up with the two equal partitions and each part had size of $7.65 \times 2.7 \times 1.0$ meters, and part one of model 2 was built up of soil-A, and part two of the model 2 was built up of soil-B. The threedimensional models with mesh on all parts of archetype are shown in figure 3, two different sizes of the mesh were employed to study the soil-structure under seismic response with half-height embedded foundation in the soil.

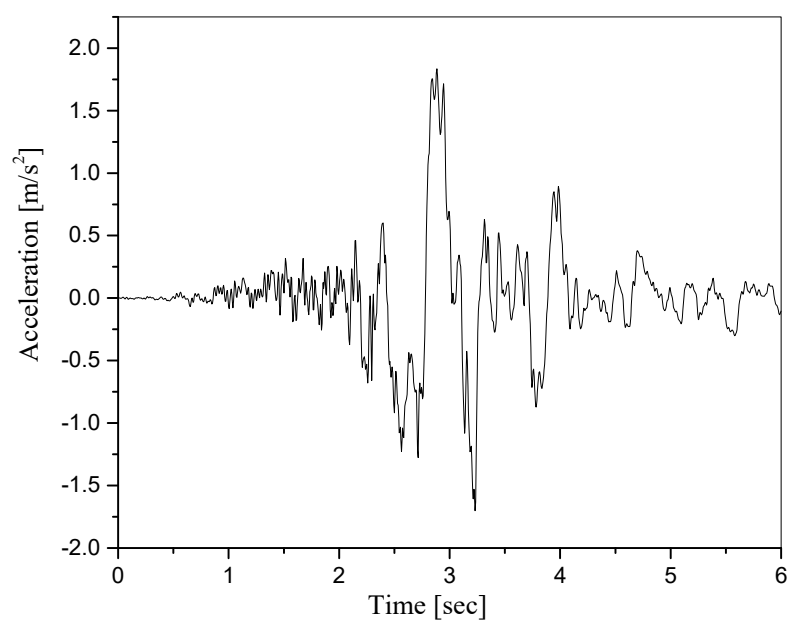

Figure 1: Acceleration history of near-fault ground motion is applied in the numerical simulation [22]. 

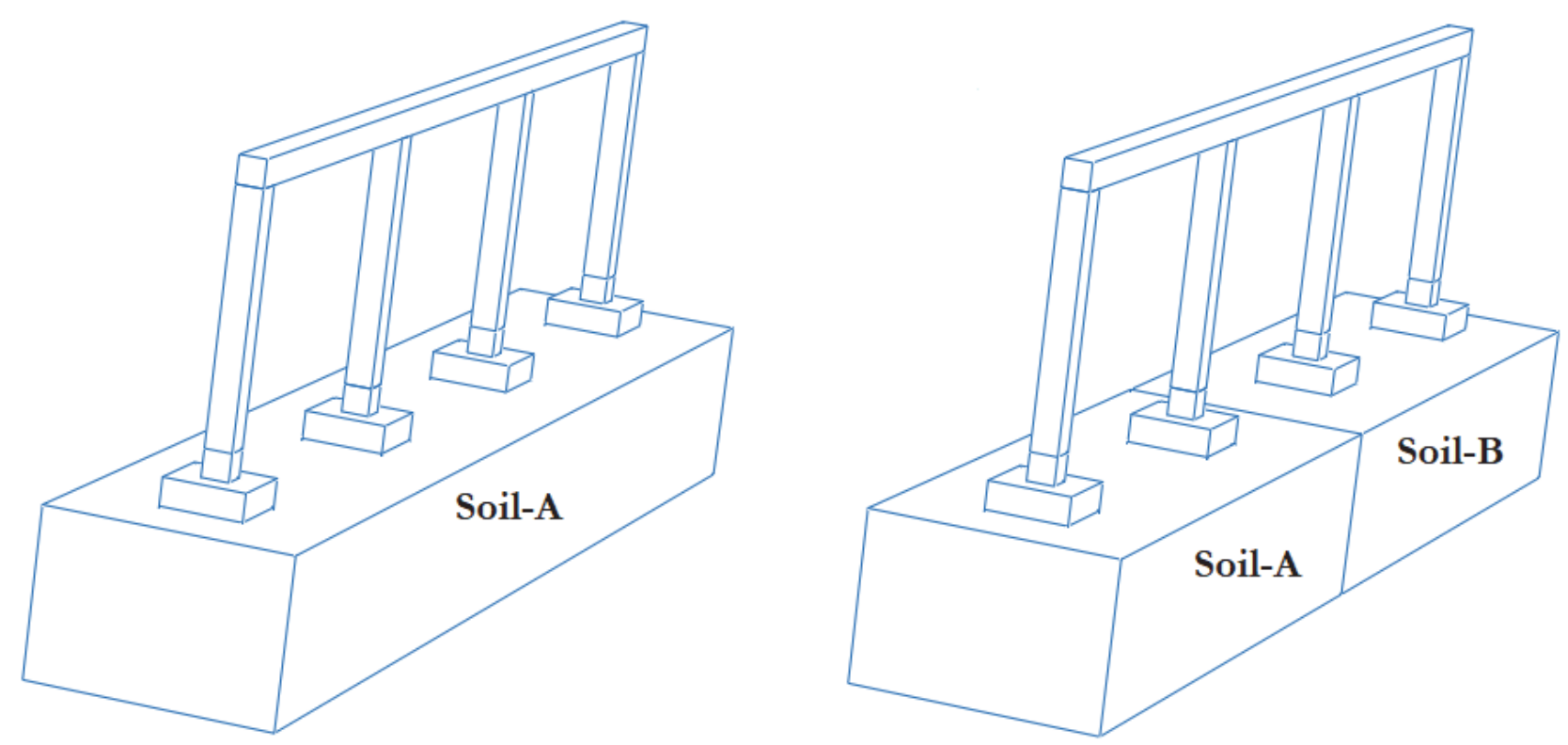

Figure 2: The soil configuration and timber frame archetype used in the numerical simulation.

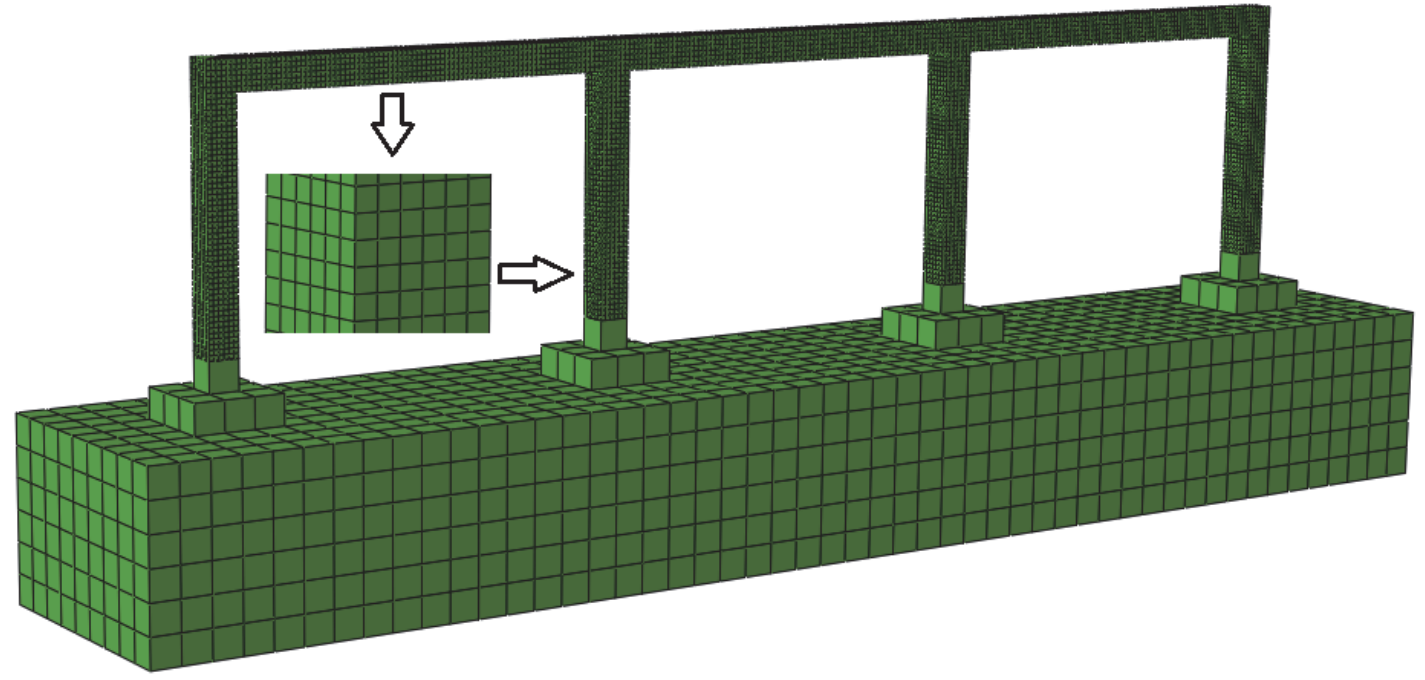

Figure 3: The mesh is developed for the numerical simulation

\begin{tabular}{|c|c|c|c|c|c|c|}
\hline $\begin{array}{l}\text { Type of } \\
\text { material }\end{array}$ & $\begin{array}{l}\text { Modulus } \\
\text { elasticity, } \\
\mathrm{E}(\mathrm{MPa})\end{array}$ & $\begin{array}{l}\text { Poisson's } \\
\text { ratio, } v\end{array}$ & $\begin{array}{l}\text { Unit weight, } \\
\gamma\left(\mathrm{kN} / \mathrm{m}^{3}\right)\end{array}$ & $\begin{array}{l}\text { Cohesion, } \\
\text { C (kPa) }\end{array}$ & $\begin{array}{c}\text { Friction } \\
\text { angle, } \\
\phi \\
\text { (degree) }\end{array}$ & $\begin{array}{c}\text { Dilatancy } \\
\text { angle, } \psi \\
\text { (degree) }\end{array}$ \\
\hline Timber & 6750 & 0.30 & 7.00 & - & - & - \\
\hline Soil-A & 131 & 0.34 & 21.4 & 0.08 & 46 & 20 \\
\hline Soil-B & 78 & 0.31 & 18.3 & 20 & 10 & 4 \\
\hline
\end{tabular}

Table 1: Soils and timber mechanical properties. 


\section{INTERPRETATION OF THE NUMERICAL SIMULATION RESULTS}

$\mathrm{I}$ $\mathrm{n}$ this study, the main objective is to examine the effects of soil-structure interaction on strain energy development which leads to inelastic and elastic displacements forming of a continuous timber beam installed on a timber frame that contained three spans, four equal columns, footing and foundation. In the numerical analysis, the applied seismic loading was not the same as the soil and structural response, the configuration of the model played a key function in seismic response. The multilayered soils interact was responsible for the displacement, the deformation, and the strain energy transfer mechanism; however, this process-controlled failure and vibration patterns of the frame. The structure was extremely vibrated with the modification of seismic loading excitation. The softened and hardening soil layers interaction developed the shear modulus with characterized nonlinearly and the transmitted near-fault ground motion exhibited differently at each archetype; however, the geometrical and mechanical characteristics of the soil and structure controlled the structural elements seismic response. Figure 4 shows the load versus the cyclic displacement of the continuous beam in models 1 and 2. In model 1 the soil foundation built up from the type A soil, while in the second model the soil foundation configuration contained types A and B soils. The continuous beam exhibited higher differential displacement in the archetype 2 . The differential displacement was represented by two models for each model; they appeared with a different mechanism. In the first model the symmetric differential displacement occurred and in the second model the differential displacement of the continuous beam took place with nonsymmetrical morphology, so the soil foundation changes significantly influenced the continuous beam differential displacement morphology. According to the table 1, the mechanical properties reported for soil types A and B were not the same, and the type-A soil exhibited higher strength and stiffness compared to the type-B soil, on the other words the stiffness and strength changes of the soil were used in the built-up soil foundation, and it caused the modification of the soil displacement morphology, and also this modification of displacement was transferred to the continuous beam and all structural elements. Based on the soil-structure seismic response for analysis displacement morphology of the continuous beam, the numerical analysis showed that the near-fault ground motion interacted with the different soil foundations and resulted in inelastic displacement ratios. The differential displacement mechanism of soil was associated with soil-structure interaction, and differential displacement mechanism of soil influenced the continuous beam seismic resistance. The interesting point is that the ground motion led to differential displacement and the subsoil morphology accelerated the differential displacement if the subsoil contained more types of the soil. The unallowable differential displacement across the continuous beam maybe caused the breaking up of the structural elements and minor and major damage on the wall surface in a timber structured building. Increasing the differential displacement generally led to the appearance of shear crack on the building timber structured wall, while the linear differential displacement did not cause the shearing crack on the timber structured building. The shearing crack was associated with seismic excitation when the seismic wave was strengthened in relation to subsoil characteristics. After the initial displacement due to the seismic excitation model, the nonlinear cyclic displacements at each model related to changing hysteretic damping and led to occurrence of the peak displacement. Increasing hysteretic damping in the continuous beam with attention to the capacity of differential displacement structural elements, the plastic displacement at each point of the structural element was predictable.
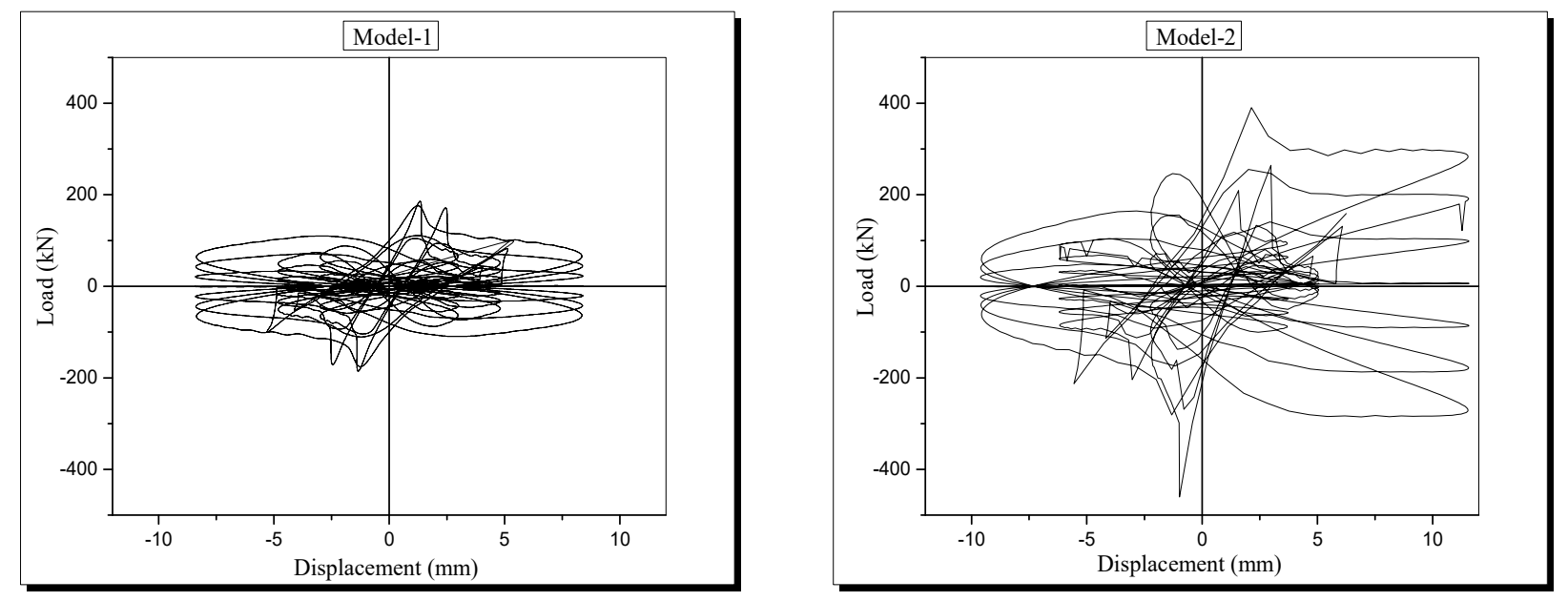

Figure 4: Load Vs displacement on timber beam models. 
Figure 5 shows the strain versus the cyclic displacement of the continuous beam in models 1 and 2 . The strain energy distribution had two different magnitudes in both models. The strain energy releasing in model 2 was higher than model 1 , the soil layers interaction increased the quantity of strain energy releasing, and this process led to increasing differential displacement of the continuous beam. The mechanical properties of the two soil layers were responsible for damping magnitude, and the damping magnitude would cause the displacement mechanism. The geometry of the soil foundation along with the two soil layers interaction supported increasing total strain energy differently at each model, and the vibration transferring from the soil foundation to structural elements behaved differently. The strain-displacement graphs were applicable in predicting shearing deformations of a continuous beam in a timber frame structure. The variation of the strain energy at failure controlled shear deformation and modified the strength and stiffness of the timber beam; afterward, the displacement of the beam at each model exhibited differently. The strain energy confinement of the timber and the soil collaborated in displacement development; the configuration soil layers were associated with the strain energy transfer and the soil-structure effect by the strain energy confinement in the soil foundation. The soil-structure interaction, the soil layers interaction, the near-fault ground motion and the mechanical properties of the soil at different locations of the soil foundation are fundamental parameters to recognize structural element strain-displacement behavior. In order to provide guidance to seismic design for soil-structure interaction, the strain has been correlated to all sections of ground accelerations for realizing displacement of the continuous timber beam. Along with soil-structure interaction, the soil layers interaction played a significant role in seismic continuous timber beam design. Soil-structure damping ratio depended on the average induced strain energy and it was associated with the decrease factors for the soil seismic strength and the occurrence of the soil foundation differential displacement.
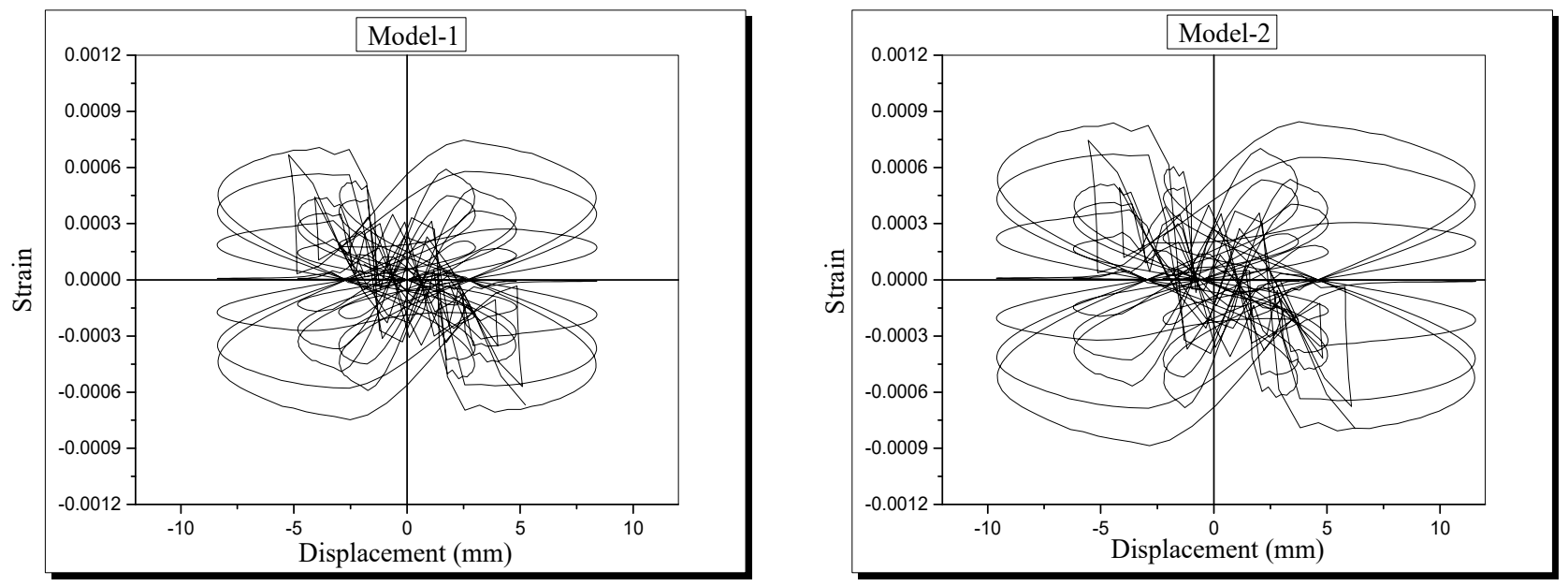

Figure 5: Strain Vs displacement on timber beam models.

Figure 6 shows the load versus the strain of the continuous beam in the models 1 and 2 . The state-of-the-art numerical analysis was performed using the finite element method to depict load-strain cyclic graphs, and there is a meaningful relationship between seismic load response and strain in the comparative seismic resistance of all simulated models. In order to evaluate health monitoring timber structure frame through assessment soil-structure interaction, it required to clearly realize the load response, strain and displacement developed by internal and external forces interaction of each simulated model. The study has shown that the soil-structure interaction was effective in increasing induced strains and load in the continuous beam. Soil layers interaction with modification of seismic wave relationship induced strains energy mechanism and resulted in the highest strains due to increased forces interaction in the timber frame. In the present study, the results of the finite element model deeply provided load, displacement and strain at different locations of the continuous beam when the near-fault ground motion interacted with the different soil foundation and the seismic excitation transferred to all parts of the soil foundation and the timber frame. The results of this numerical simulation were very difficult to achieve under laboratory conditions with this accuracy of the structural element seismic simulation. Due to the triggering high level of nonlinear strain energy in the model 2, the soil faced the high level of seismic vibration compared to the model 1 , eventually higher strain energy dissipation occurred in the model 2; however, the high level of triggering and dissipation of strain energy caused the soil vibration and this vibration mechanism of the soil was transferred to the frame. The vibration stiffness of soil against differential displacement and nonlinear deformation restrained frame seismic excitation mechanism. 

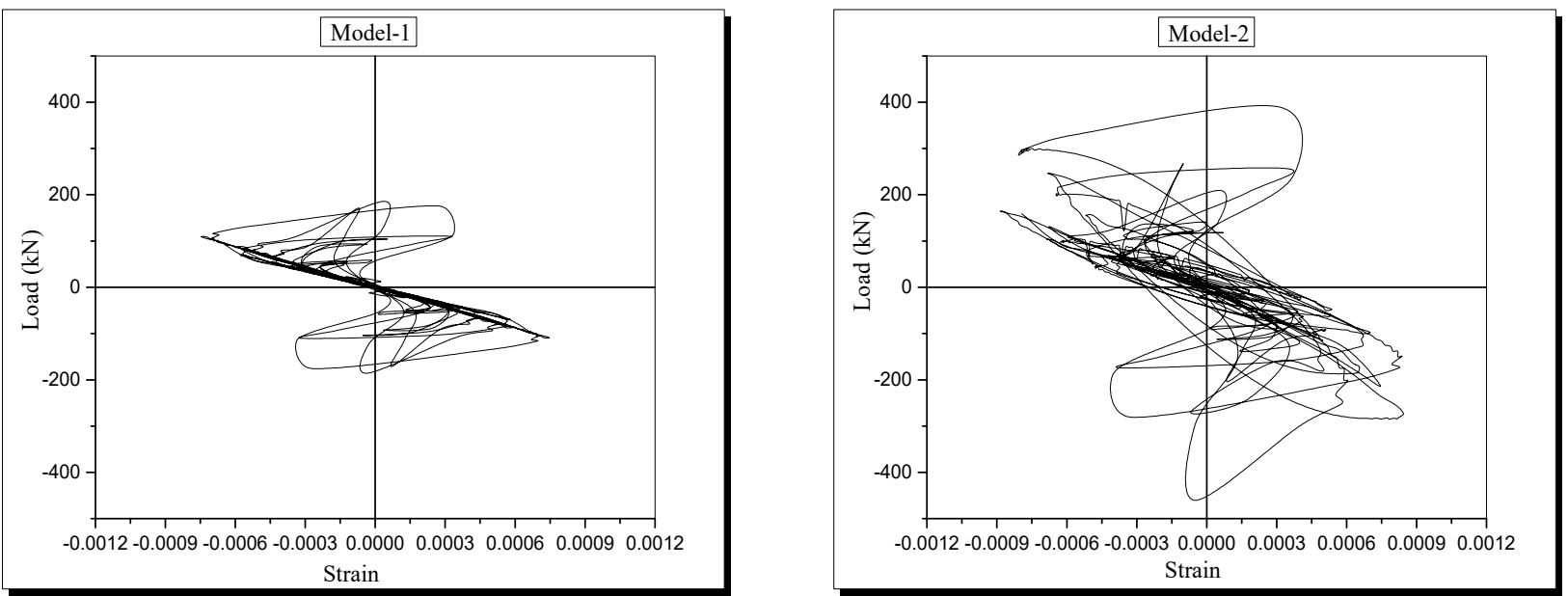

Figure 6: Load Vs strain displacement on timber beam models.

\section{CONCLUSION}

$\mathrm{I}$ $\mathrm{n}$ the most of urban construction site, the buildings show different seismic response and result in various seismic resistance of different structures while the applied near-fault ground motion used from the station for earthquake data collection is the same, and also the urban construction sites always contain different soil layers. In the seismic design of the structure, the underground simulation is extremely important. In the present study, the following goals have been achieved for enhancement timber frame seismic design.

- For the urban construction site, to use an accurate near-fault ground motion is required for the seismic design for each individual building, in order to provide sufficient seismic stability of the structure. The results showed that the near-fault ground motion characteristics changed with the site morphology and effected seismic stability of the structure significantly.

- In the first model of the numerical simulation, the symmetric differential displacement occurred and in the second model the differential displacement of the continuous beam took place with nonsymmetrical morphology. The changes of soil foundation characteristics significantly influenced the continuous beam differential displacement morphology.

- The stiffness and strength modification of the soils were used in the built-up soil foundation and it caused variation of the soil foundation displacement morphology, and also this modification of soil foundation displacement was transferred to the structural elements and each part of the continuous beam faced different morphology of the differential displacement.

- The soil-structure seismic based on the near-fault ground motion interacted with the different soil foundation. The soil foundation with different layers resulted in inelastic displacement ratios modification and subsoil effect on continuous beam strength reduction in association with the soil-structure systems. The enhancement of the soil layers interaction significantly improved timber frame stability.

- The soil-structure interaction, the soil-layers interaction, the near-fault ground motion and the mechanical properties of the soil at different locations of the soil foundation were fundamental parameters to recognize structural element strain-displacement in seismic timber design. Soil-structure damping ratio depended on the average induced strain energy and was associated with the decrease factors for the soil seismic strength and the occurrence of the differential displacement of the soil foundation.

- The numerical analysis results provided load, displacement and strain at different locations of the continuous beam when the beam was subjected to seismic excitation, which was very difficult to achieve under laboratory conditions with this accuracy of the structural element seismic simulation. The numerical analysis is a cost-effective technique with high accuracy to solve scientific problems. 


\section{REFERENCES}

[1] Namdar, A., Pelko, A. K. and Nusrath, A. (2010). Liquefaction mathematical analysis for improvement structures stability, Fract Struct Int, 4(14), pp. 75-80. DOI: 10.3221/IGF-ESIS.14.08.

[2] Namdar, A. and Nusrath, A. (2010). Tsunami numerical modeling and mitigation, Fract Struct Int, 4 (12), pp. 57-62. DOI: $10.3221 /$ IGF-ESIS.12.06.

[3] Namdar, A. and Feng, X. (2014). Evaluation of safe bearing capacity of soil foundation by using numerical analysis method, Fract Struct Int, 8 (30), pp. 138-144. DOI: 10.3221/IGF-ESIS.30.18.

[4] Namdar, A. and Pelko, M. K. (2009). Numerical analysis of soil bearing capacity by changing soil characteristics, Fract Struct Int, 3 (10), pp. 38-42. DOI: 10.3221/IGF-ESIS.10.05.

[5] Zhelnin, M., Kostina, A., Plekhov, O., Panteleev, I. and Levin, L. (2019). Numerical analysis of application limits of Vyalov's formula for an ice-soil thickness, Fract Struct Int, 13(49), pp. 156-166. DOI: 10.3221/IGF-ESIS.49.17.

[6] Li, Y., Zhang, K., Liu, B. and Pan, Z. (2015). On the decay of strength in Guilin red clay with cracks, Fract Struct Int, 9(34). DOI: 10.3221/IGF-ESIS.34.66.

[7] Namdar, A. and Pelko, M. K. (2009). Bearing capacity of mixed soil model, Fract Struct Int, 3 (7), pp. 73-79. DOI: $10.3221 /$ IGF-ESIS.07.06.

[8] Lazzarin, P., Livieri, P., Berto, F. and Zappalorto, M. (2008). Local strain energy density and fatigue strength of welded joints under uniaxial and multiaxial loading. Eng Fract Mech, 75 (7), pp. 1875-1889. DOI: 10.1016/j.engfracmech.2006.10.019.

[9] Nicola Bonora, Domenico Gentile, Pietro Paolo Milella, Golam Newaz, Francesco Iacoviello. (2000). Ductile damage evolution under different strain rate conditions. Appl. Mech. Div. ASME, 246, pp 145-154.

[10] Panin, S., Vinogradov, A., Moiseenko, D., Maksimov P., Berto, F., Byakov, A., Eremin, A., Narkevich. N., (2016). Numerical and Experimental Study of Strain Localization in Notched Specimens of a Ductile Steel on Meso- and Macroscales, Adv Eng Mater, 18(12), pp. 2095-2106. DOI: 10.1002/adem.201600206.

[11] Boniardi, M., Tagliabue, C. and Venturini, N. (2006). Residual stress origin: Plastic deformation and machining, Metall Ital, 98(11), pp. 53-60.

[12] Namdar, A., Dong, Y. and Liu, Y. (2019). The effect of nonlinearity of acceleration histories to timber beam seismic response, Mater Des Proces Communic, 1 (2), pp. 1-4. DOI:10.1002/mdp2.53.

[13] Ayatollahi, MR., Rashidi Moghaddam, M. and Berto, F. (2015). A generalized strain energy density criterion for mixed mode fracture analysis in brittle and quasibrittle materials, Theor Appl Fract Mec, (79), pp. 70-76. DOI: $10.1016 /$ j.tafmec.2015.09.004.

[14] Košíková, B., Sláviková, E. and Sasinková, V. (2006). The use of various yeast strains for removal of pine wood extractive constituents, Wood Res. 51(4). pp. 47-54.

[15] Iacoviello, F., Di Cocco, V. and Cavallini, M. (2015). Fatigue crack tip damaging micromechanisms in a ferriticpearlitic ductile cast iron, Fract Struct Int, 9(33), pp. pages 111-119. DOI: 10.3221/IGF-ESIS.33.15.

[16] Berto, F. and Foti, P. (2019). Evaluation of the Strain Energy Density Value without the Construction of the Control Volume in the Preprocessing Phase of the Finite Element Analysis, Proc Struct Integ, (18), pp. 183-188. DOI: $10.1016 /$ j.prostr.2019.08.152.

[17] Berto, F. and Razavi, J. (2019). Fatigueless structures inspired by nature: A case study, Mater Des Proces Communic, 1 (3), pp. 1-3. DOI: org/10.1002/mdp2.27.

[18] Iacoviello, F., di Cocco, V., Cavallini, M., Marcu, T. and Molinari, A. (2005). Influence of sintered stainless steel microstructure on fatigue crack paths, Fatigue Fract Eng M, 28(1-2), pp. 187-193. DOI: 10.1111/j.1460-2695.2005.00836.x.

[19] Adelaide Parisi, M. and Piazza, M. (2015). Seismic strengthening and seismic improvement of timber structures, Constr Build Mater, 97 (30), pp. 55-66. DOI: 10.1016/j.conbuildmat.2015.05.093.

[20] Namdar, A., Darvishi, E., Feng, X., Zakaria, I. and Yahaya, F.M. (2016). Effect of flexural crack on plain concrete beam failure mechanism - A numerical simulation. Fract Struct Int, 10 (36), pp. 168-181. DOI: 10.3221/IGF-ESIS.36.17.

[21] Bellini, C., Di Cocco, V., Iacoviello, F. and Sorrentino, L. (2019). Experimental analysis of aluminium/carbon epoxy hybrid laminates under flexural load, Fract Struct Int, 13(49), pp. 739-747. DOI: 10.3221/IGF-ESIS.49.66.

[22] https://strongmotioncenter.org/ 